\title{
Characterization and cloning of the gerC locus of Bacillus subtilis 168
}

\author{
Mohammed A. Yazdi $\dagger$ and ANNe MoIR* \\ Krebs Institute, Department of Molecular Biology and Biotechnology, University of Sheffield, Sheffield S1O 2TN, UK
}

(Received 27 November 1989; revised 15 February 1990; accepted 12 March 1990)

\begin{abstract}
A Bacillus subtilis gerC spore germination mutant demonstrating a temperature-sensitive response to $\mathrm{L}$-alanine as germinant has been characterized in detail. The gerC58 mutation is $50 \%$ cotransformed with aroB in the gene order $\operatorname{ger} C$-aroB-trpC. The mutation is responsible for a severe growth defect which is manifest at all growth temperatures and is most extreme on rich media. A second, unlinked, mutation in the original strain suppressed this growth defect, but spores of the suppressed strain failed to germinate in alanine at $42{ }^{\circ} \mathrm{C}$. As this germination defect is dependent on the presence of the $g e r C 58$ allele, it is likely to be the direct result of a mutant gerC protein. The gerC gene therefore appears to have a role in both spore germination and vegetative cell growth. A gene library of $B c I$-digested B. subtilis chromosomal DNA was constructed in phage vector $\phi 105 \mathrm{~J} 27$. A derivative containing the gerC region was obtained by complementation of the growth defect of an unsuppressed ger $C 58$ strain. This phage contained a $6.3 \mathrm{~kb}$ insert of bacterial DNA, which is above the reported packaging limit of the phage. It failed to form visible plaques, although it could be handled as a prophage and sufficient phage particles be isolated to allow characterization of the insert. A deletion derivative generated in vitro and carrying only $2.9 \mathrm{~kb}$ of insert DNA also complemented the $g e r C$ defect. This gerC locus is the second locus to be implicated in alanine-stimulated germination. The first, ger $A$, is a developmentally controlled operon whose gene products are present only in the spore. This study of ger $C$, in contrast, reveals a role in spore germination for a normally essential vegetative protein.
\end{abstract}

\section{Introduction}

A number of genetic loci in Bacillus subtilis whose products are important in spore germination have been identified by mutant analysis (Piggot $e t$ al., 1981). Of the loci concerned, two have been identified that are only defective in germination in alanine; these are ger $A$ and gerC. Both were described in the first analysis of ger mutants, by Trowsdale \& Smith (1975). The gerA locus has been studied in detail, Sammons et al. (1981) suggesting that the properties of gerA mutants were consistent with the hypothesis that the locus could encode an alanine-sensitive receptor in the spore. The region was cloned (Moir, 1983) and has been sequenced (Feavers et al., 1985; Zuberi et al., 1987). The gerA operon comprises three genes whose products are likely to be membrane associated; expression of these genes is confined to the forespore compartment during sporulation (Feavers et al., 1990).

The gerC locus has been studied in much less detail; the original report described two mutations, gerC58 and

† Present address: Department of Biochemistry, Clayton Foundation Biochemical Institute, University of Texas, Austin, Texas 78712, USA.
gerC88, both of which conferred temperature-sensitive spore germination in alanine.

Attempts to carry out precise mapping of the $\operatorname{gerC}$ mutations (Moir et al., 1979) were frustrated by the presence of a number of mutations in the strains, all cotransducible with the ger marker. The first complication in the strains was the presence (within the starting strain from which the mutants were derived) of an allele blocking the spore germination response at an intermediate stage. This locus was called $t z m$ by Trowsdale $\&$ Smith (1975) and later designated gerJ and characterized as a member of a class of cortex-defective mutants (Warburg \& Moir, 1981; Warburg et al., 1986). It leads to a decreased loss of optical density during germination and a pink colouration in the germination plate test involving reduction of a tetrazolium salt.

The original gerC mutant isolates grew abnormally on rich agar; at $42{ }^{\circ} \mathrm{C}$ the colonies were extremely small, whereas at $30^{\circ} \mathrm{C}$ they were of normal size (the $\mathrm{Wrd}^{-}$ phenotype). On minimal glucose medium these colonies were normal at all temperatures tested. As both growth in rich agar and germination were temperature sensitive, it was originally thought that both might result from a single mutation. Moir et al. (1979) carried out PBS1 
transduction crosses, using $l y s^{+}$as the selected marker, which succeeded in separating both gerJ and wrd mutations from gerC. Transductants that were $\mathrm{Wrd}^{-}$but $\mathrm{Ger}^{+}$, for example, were obtained in the cross. The gerC defect was only found in transductants that had also acquired the donor $\operatorname{trp} C$ marker, placing the mutation very close to or on the lys-distal side of trp. Lys ${ }^{+}$ transductants that were $\mathrm{GerC}^{-}$had also acquired the donor wrd and gerJ mutations, and thus this cross, while establishing the gene order lys-wrd-gerJ-(gerC, trp) did not yield any gerC mutants that were free from the linked mutations.

This paper contains a reassessment of the gerC locus and describes the successful separation of a $\operatorname{ger} C$ mutation from the linked but independent mutations. The unexpected discovery of a severe growth defect associated directly with gerC allowed the selection of clones carrying the wild-type complementing gene.

\section{Methods}

Bacterial strains used are listed in Table 1. Routine subculture of strains was done in Difco Penassay broth (PAB) or on Oxoid nutrient agar no. 2 (NA) plates, unless otherwise stated in the text. Glucose minimal medium (MA) for the selection of transformants was that of Anagnostopoulos \& Spizizen (1961) supplemented with amino acids as required. Media for the culture of phage 105 derivatives were described by Errington \& Jones (1987). Brain heart infusion broth (BHIB; Oxoid) was used for the preparation of phage 105 lysates. BBL trypticase (Moir \& Brammar, 1976) was used for gerC $^{+}$selection.

Transformation of competent cells. This was done as described by Warburg \& Moir (1981). Recombinants selected were purified by single-colony isolation on selective medium before testing of unselected markers. The tetrazolium reaction used to score $\mathrm{Ger}^{+}$and $\mathrm{Ger}^{-}$ colonies as Tzm-red or -white, respectively, was as described previously (Zuberi et al., 1985) except that lysogens of $\phi 105 \mathrm{~J} 27$, MY1 and MY2 were incubated for $4 \mathrm{~d}$ at $30^{\circ} \mathrm{C}$ to obtain sporulation in colonies.

PBS1 transduction. This was according to Jamet \& Anagnostopoulos (1969).

Spore germination studies. Spores were prepared on NA plates and washed as described by Moir et al. (1979). Germination was monitored as loss of $\mathrm{OD}_{580}$ after addition of germinants, by the procedure described in Moir et al. (1979), except that Tris/ $\mathrm{HCl}$ was $10 \mathrm{mM}, \mathrm{pH} 8.4$ and $\mathrm{KCl}$ was $2.25 \mathrm{mg} \mathrm{ml}^{-1}$.

Construction of a gene library, protoplast transfection and induction of lysogens. These procedures were according to Errington \& Jones (1987). Lysogeny was tested by cross-streaking against a $\phi 105$ clear mutant.

Complementation of the 'tiny' (Tny) phenotype is explained in the text; for spot complementation tests, $10 \mu \mathrm{l}$ aliquots of small-scale induced lysates or of an appropriate dilution of a purified phage preparation were spotted onto a lawn of Tny- cells spread on NA, along with a separate vector control. Results were scored after $24-48 \mathrm{~h}$ incubation at $30^{\circ} \mathrm{C}$.

\section{Results and Discussion}

Previous attempts to separate gerC from its linked mutations had utilized PBS1 transduction, selecting Lys $^{+}$. A PBS1 cross selecting MetB ${ }^{+}$was attempted in the hope of obtaining gerC mutants without linked secondary mutations by selecting a marker on the side of the region opposite to lys. The results were still difficult to interpret in terms of gene order for both gerC 58 and gerC 88 donor strains; as transductants carrying gerC58 showed less residual germination at the non-permissive temperature, this marker was chosen for further study.

Table 1. Strains of Bacillus subtilis 168

\begin{tabular}{|c|c|c|}
\hline Strain & Genotype & Origin or reference \\
\hline 1604 & $\operatorname{trp} C 2$ & Moir et al. (1979) \\
\hline BD111 & cysB3 thrA5 trpC2 & D. Dubnau \\
\hline CU267 & ilvB2 leuB16 trpC2 & S. Zahler \\
\hline CU1064 & met $B 5$ att $\mathbf{S P} \beta$ & S. Zahler \\
\hline 1558 & gerC58 wrd tzm(gerJ5l) trpC2 & Trowsdale \& Smith (1975) \\
\hline AM677 & thr A5 trpC 2 gerC 58 (suppressed) & This work \\
\hline QB99 & hisH2 leuA8 & $1 \mathrm{~A} 89$ of BGSC \\
\hline $1 \mathrm{~A} 563$ & $\operatorname{trpB7}$ & BGSC \\
\hline SB70 & tyrAl hisH2† & $1 \mathrm{~A} 173$ of BGSC* \\
\hline SB137 & aroB2 hisH2† & Nester et al. (1963) \\
\hline AM726 & tyrAl hisH2 ger $^{+}$ & PBS1 [SB70] $\rightarrow$ CU1064 \\
\hline AM727 & aroB2 hisH $2 \mathrm{ger}^{+}$ & PBS1 [SB137] $\rightarrow$ CU1064 \\
\hline BG4004 & $\operatorname{argC4} m \operatorname{mtr}-264$ amyE: $:\left[\mathrm{P}_{t r p} \operatorname{trp} E^{\prime}-l a c Z^{\prime} \mathrm{Cm}^{\mathrm{R}}\right]$ & Shimotsu \& Henner (1986) \\
\hline NG17.23 & spoIVA67 trpC2 & Piggot \& Coote (1976) \\
\hline FB75 & ecp-1 & Raugei et al. (1981) \\
\hline AM355 & $\operatorname{ger} A 570 \operatorname{trp} C 2$ & Zuberi (1985) \\
\hline
\end{tabular}

* Bacillus Genetic Stock Center, Department of Microbiology, Ohio State University, Columbus, Ohio 43210, USA.

† These strains already carry a spontaneous germination mutation that maps in gerA (A. Moir, unpublished results). 

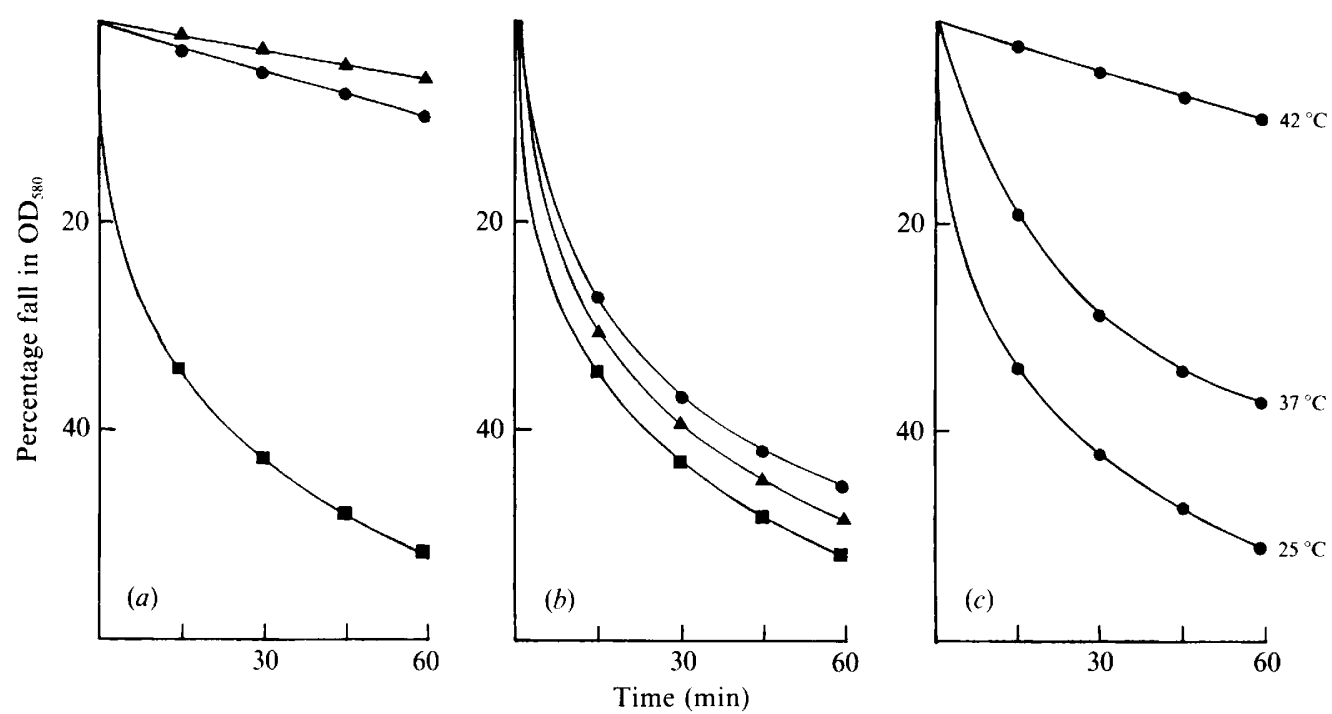

Fig. 1. Germination of AM677. Spores of AM677 (gerC58)(O), $1604\left(\mathrm{ger}^{+}\right)(\mathbf{0})$ and AM355 (gerA570) (A) prepared at the same time under the same conditions were heat-activated at $80^{\circ} \mathrm{C}$ for $20 \mathrm{~min}$ in distilled water and germinated in: $(a)$ alanine and $\mathrm{KCl}$ at $42^{\circ} \mathrm{C}$, (b) asparagine, glucose, fructose and $\mathrm{KCl}$ at $42^{\circ} \mathrm{C}$, and $(c)$ alanine and $\mathrm{KCl}$ at 25,37 and $42^{\circ} \mathrm{C}$.

An attempt was made to transfer the gerC58 mutation into an unmutagenized background by congression. The original strain 1558 was used as source of donor DNA (final concentration $20 \mu \mathrm{g} \mathrm{ml}^{-1}$ ) in a transformation cross with strain BD111 as recipient; $\mathrm{Cys}^{+}$transformants were selected on minimal agar containing tryptophan and threonine, purified and tested for germination phenotype by the tetrazolium plate test. Only three out of 643 transformants were Tzm-white and grew to a normal extent on rich agar. About $3 \%$ of the transformants had a severe growth defect on NA and did not sporulate; these were not studied further at the time.

The three Tzm-white transformants were characterized and shown to possess a temperature-sensitive defect in alanine-stimulated germination like the parental strain (Fig. 1). One of these, strain AM677, was used as a starting point for more detailed mapping by transformation crosses.

The results of transformation crosses between AM677 and strains carrying auxotrophic markers in the trp region revealed an unexpected asymmetry of behaviour. If AM677 was the recipient strain, Tzm-white recombinants were obtained amongst the transformants. If, in contrast, this strain was used as donor, no such transformants were obtained, and instead a significant proportion of the recombinants grew as visible but very small colonies on the minimal selective agar (dubbed the 'tiny' or Tny- phenotype; colony diameter was about one-fifth that of $\mathrm{Tny}^{+}$). The results of several crosses are shown in Table 2.
Cross 1, using strain AM677 as recipient, demonstrates that the likely gene order is gerC-trpC-hisH. Cross 2, using this strain as donor, generates the gene order tny-trpC-hisH, where the tny mutant allele is responsible for the growth defect of recombinants and shows similar transformation linkage to that in cross 1 for $\operatorname{ger} C$. Cross 3 is a control, showing that strain 1604 does not carry a tny mutant allele linked to trpC. Cross 4 confirms and extends the gene order $\operatorname{gerC}(\operatorname{tny})-\operatorname{trp} C$ hisH-tyrA. The overall deduced map location of $\operatorname{ger} C$, based on these and other crosses with strains AM727 and 1A563 (Yazdi, 1989), is summarized in Fig. 2.

gerC and tny markers map close together, and have not been separated in any of our transformation crosses. In crosses 2 and 4 of Table 2, and in other unpublished crosses, all $\mathrm{Tny}^{+}$recombinants tested (at least 300 ) were $\mathrm{Ger}^{+}$. In order to test whether $\mathrm{Ger}^{-}$recombinants from cross 1 carried the tny mutant allele, chromosomal DNA was isolated from four $\mathrm{Ger}^{-} \mathrm{His}^{+}$and four $\mathrm{Ger}^{+} \mathrm{His}^{+}$ recombinants from cross 1 in Table 2. These DNAs were used to transform strain QB99 (leuA8 his H2) to $\mathrm{His}^{+}$. At least 200 transformants from each of the eight crosses were tested for unselected markers. Whenever a Ger+ donor was used, none of the recombinants were $\mathrm{Tny}^{-}$. If a gerC mutant donor was used, however, about $20 \%$ of the transformants had the characteristic $\mathrm{Tny}^{-}$growth defect. Thus the $\operatorname{ger} C$ mutant allele and the tny mutant allele had segregated together in all of the eight transformants tested from cross 1 . The genetic data suggest, but do not unequivocally prove, that gerC 58 and 
Table 2. Mapping of gerC58 by transformation

\begin{tabular}{|c|c|c|c|c|c|c|}
\hline Cross & Donor & Recipient & Selection & $\begin{array}{l}\text { Transformant } \\
\text { class }\end{array}$ & $\begin{array}{l}\text { No. of crossovers } \\
\text { required for } \\
\text { predicted gene order* }\end{array}$ & $\begin{array}{c}\text { No. of } \\
\text { transformants }\end{array}$ \\
\hline 1 & $\begin{array}{l}\text { QB99 } \\
\quad(\text { leuA8 hisH2) }\end{array}$ & $\begin{array}{l}\text { AM677 } \\
\quad(g e r C 58 \text { thrA5 trpC2) }\end{array}$ & $\operatorname{Trp}^{+}$ & $\begin{array}{l}\mathrm{His}^{+} \mathrm{Ger}^{-} \\
\mathrm{His}^{+} \mathrm{Ger}^{+} \\
\mathrm{His}^{-} \mathrm{Ger}^{-} \\
\mathrm{His}^{-} \mathrm{Ger}^{+}\end{array}$ & $\begin{array}{l}2 \\
2 \\
2 \\
2\end{array}$ & $\begin{array}{l}23 \\
15 \\
32 \\
30\end{array}$ \\
\hline 2 & AM677 & QB99 & $\mathrm{His}^{+}$ & 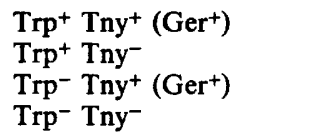 & $\begin{array}{l}2 \\
4 \\
2 \\
2\end{array}$ & $\begin{array}{r}31 \\
1 \\
50 \\
18\end{array}$ \\
\hline 3 & $\begin{array}{l}1604 \\
(\operatorname{trp} C 2)\end{array}$ & QB99 & His $^{+}$ & $\begin{array}{l}\text { Trp }^{+} \text {Tny }^{+}\left(\mathrm{Ger}^{+}\right) \\
\text {Trp }^{+} \text {Tny } \\
\text { Trp }^{-} \text {Tny } \\
\text { Trp } \\
\text { Trer } \\
\text { Tny }^{-}\end{array}$ & NA & $\begin{array}{r}28 \\
0 \\
72 \\
0\end{array}$ \\
\hline 4 & AM677 & $\begin{array}{l}\text { AM726 } \\
\text { (tyrAl hisH2) }\end{array}$ & Tyr $^{+}$ & 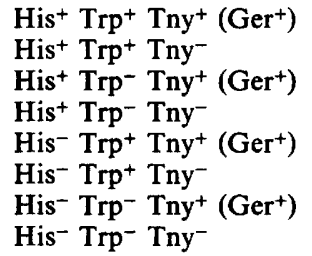 & $\begin{array}{l}2 \\
4 \\
2 \\
2 \\
2 \\
4 \\
4 \\
4\end{array}$ & $\begin{array}{r}22 \\
0 \\
55 \\
9 \\
15 \\
1 \\
2 \\
1\end{array}$ \\
\hline
\end{tabular}

NA, Not applicable - tny marker not segregating in cross.

* Predicted gene order is: cross 1, gerC-trpC-hisH; cross 2, thy-trpC-hisH; cross 4, gerC (tny)-trpC-hisH-tyrA.

tny represent the same mutational site; if they do not, they must map extremely close to each other. The analysis is made more difficult by the failure of the unsuppressed tny mutant to sporulate - so that the Ger phenotype can only be scored in $\mathrm{Tny}^{+}$recombinants or in suppressed backgrounds. The cotransfer of the gerC marker with $t n y^{+}$in all of over 300 recombinants does suggest that the mutations are very close, if not identical. Our failure to separate them makes recombination index analysis impossible, and reversion analysis of $\mathrm{Tny}^{-}$is complicated by the observed suppression. The simplest interpretation consistent with all our observations is that the two phenotypes result from the same mutation.

Considerable effort had been expended in attempting to separate gerC58 from the growth defect; it was finally realized that the likely interpretation of our data was that strain AM677 and the original gerC mutant strain 1558 both harbour some second compensating mutation, not linked to $t r p$ in transformation crosses. This suppressed the growth defect resulting from the thy (gerC) mutation and left the strain spore-forming but germinationdefective. In retrospect, the frequent class of congressants with an abnormal growth phenotype generated in early attempts to obtain a singly mutant gerC58 strain were probably single mutants, whereas AM677 either acquired both suppressor and gerC, by a double congression event or because of linkage of the suppressor to the selected marker, or was a gerC transformant carrying a spontaneously generated suppressing mutation that arose at an early stage of colony development.

Strains carrying the unsuppressed gerC58 mutation proved very difficult to handle; any attempt to subculture them in rich medium, either in liquid or on plates, led to the rapid accumulation of suppressed mutants with improved growth rate. Cultures of the unsuppressed strain were routinely generated by inoculating together six colonies from an MA plate into $3 \mathrm{ml}$ of minimal glucose medium, and incubating at $37^{\circ} \mathrm{C}$ for about $8 \mathrm{~h}$ to generate a mid-exponential-phase culture. Liquid cultures were stable only if aerated efficiently; after $30 \mathrm{~min}$ at room temperature any unaerated culture would lyse spontaneously. Attempts to make glycerol stocks of these strains failed, as only suppressed derivatives could be recovered even after short periods of storage. Colonies of the unsuppressed strain had to be generated directly when required by transformation of strain QB99 with DNA from strain AM677, selecting $\mathrm{His}^{+}$. Transformants that were Tny $^{-}$, recognized by their small colony size on MA, were purified twice on MA and used fresh in the procedure described above.

\section{Cloning of the gerC region}

A library of $B c l I$-generated fragments of chromosomal DNA isolated from strain 1604 was generated by cloning into the BamHI site of the cloning vector $\phi 105 \mathrm{~J} 27$ (Jones 


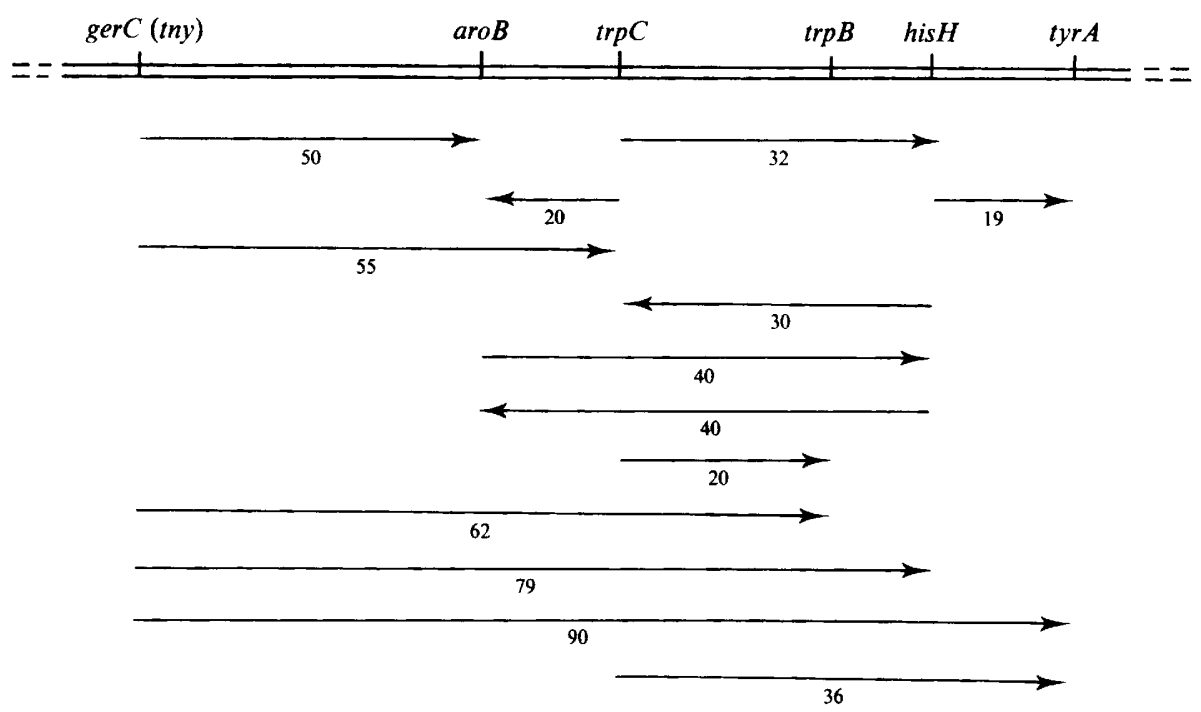

Fig. 2. The genetic map of the gerC-trp region; not drawn to scale. The numbers represent map distance $(=100-$ percentage cotransformation). The arrow points to the selected marker in each case. Where several identical crosses had been carried out, the average map distance is shown.

\& Errington, 1987). Because an unsuppressed tny (gerC58) strain grows very poorly on rich agar it was possible to detect complementation by a ger $^{+}$hybrid phage on the basis of improved growth of lysogens in plaques on NA. Tny ${ }^{-}$cells ( $100 \mu$ l aliquots), grown in minimal glucose medium to $\mathrm{OD}_{600}=0.25$ and concentrated twofold, were infected with $2 \times 10^{6}$ p.f.u. from the recombinant phage pool (or $2 \times 10^{6}$ p.f.u. of $\phi 105 \mathrm{~J} 27$ as control), and plated in a $3 \mathrm{ml} \mathrm{BBL}$ trypticase overlay on NA plates. After overnight incubation at $30^{\circ} \mathrm{C}$, the plates infected with the recombinant phage pool contained 2-15 faster-growing clusters of cells on a very thin lawn of Tny ${ }^{-}$cells; in contrast, the control infections with vector alone gave no such colonies. Any further incubation beyond the $24 \mathrm{~h}$ period permitted the growth of revertants and/or suppressed derivatives on both experimental and control plates.

Lysogens from eight of the clusters that appeared early were purified to single colonies on NA, and then heatinduced. Filter-sterilized lysates were spotted onto a lawn of Tny ${ }^{-}$cells on NA and incubated for $24-48 \mathrm{~h}$ at $30{ }^{\circ} \mathrm{C}$. Lysates derived from seven out of the eight cultures were positive, complementing the Tny ${ }^{-}$growth defect as demonstrated in Fig. 3(a). The transducing phages were purified to homogeneity through successive cycles of lysogenization of a Tny- strain, purification of individual lysogens, and induction.

Attempts to purify the transducing phages by singleplaque isolation were unsuccessful. Separate plate lysates were made from several hundred individual phage plaques obtained by plating the induced lysates on CU267; none ever showed transducing activity. The transducing phage fails to make plaques on Tny ${ }^{+}$lawns, although it was possible to see the centres of infection as heavily growing spots on Tny- lawns (Fig. $3 b$ ). Estimation of phage DNA purified from the lysate in Fig. 3(b) suggests that this plate was infected with about $10^{5}$ transducing particles; the efficiency of detection of $\mathrm{Tny}^{+}$ lysogenic centres is therefore very low. The visible plaques in lawns represent an even smaller proportion of the total titre of the lysate and represent deletion mutants. All the transducing isolates obtained showed similar complementation behaviour and lacked plaqueforming ability. One, named $\phi 105 \mathrm{MY} 1$, was retained for more detailed analysis.

Since the cloning had exploited repair of the Tnygrowth defect, it was necessary to test whether the germination defect was simultaneously complemented on lysogenization of the Tny ${ }^{-}$strain by $\phi 105 \mathrm{MY} 1$. The germination behaviour of $20 \mathrm{Tny}^{+}$complemented lysogenic transductants of an unsuppressed Tny ${ }^{-}$strain was examined in a tetrazolium overlay test. All twenty were Tzm-red and hence $\mathrm{Ger}^{+}$; the cloned DNA therefore complemented the gerC (tny) locus, repairing both growth and germination defects.

Two litres of a complemented lysogen carrying $\phi 105 \mathrm{MY} 1$ as prophage was grown in BHIB, heatinduced and the phage particles harvested by PEG precipitation, purified by centrifugation on a $\mathrm{CsCl}$ step gradient and phenol-extracted. The yield of phage DNA, $50 \mu \mathrm{g}$ from 2 litres of lysate, was only one-fortieth of that routinely obtained by induction of a vector-containing lysogen, but was sufficient for initial characterization of the inserted DNA. 
The $2.9 \mathrm{~kb}$ Sst I fragment and the $3.4 \mathrm{~kb} \mathrm{XbaI} \mathrm{fragment}$ from phage MY1 have been subcloned separately into pUC119 (M. Yazdi \& S. Greenhalgh, unpublished experiments). Additional sites defined in the cloned DNA (Fig. 4) were derived by restriction mapping of plasmid subclones.

The lack of plaque-forming ability and poor yield of phage on induction can be explained by the size of the DNA insert in $\phi 105 \mathrm{MY} 1$. The $6.3 \mathrm{~kb}$ of cloned DNA would mean that the total size of the hybrid genome, at $41.2 \mathrm{~kb}$, is $1 \mathrm{~kb}$ larger than the published upper size limit for efficient packaging of $\phi 105 \mathrm{DNA}$ in the phage head (Errington \& Pughe, 1987).

$\phi 105 \mathrm{MY} 1$ contains only two $\mathrm{XbaI}$ sites, flanking a $3.4 \mathrm{~kb}$ segment of cloned DNA at the right-hand end of the ger $C$-containing $6 \mathrm{~kb} \mathrm{BclI}$ fragment (Fig. 4). As it was likely that the failure of $\phi 105 \mathrm{MY} 1$ to make visible plaques is related to the large insert size, it was presumed that deletion of $3.4 \mathrm{~kb}$ from the insert might restore plaque-forming ability.

Five hundred nanograms of $\phi 105 \mathrm{MY} 1$ DNA was cut with $X b a \mathrm{I}$ in $20 \mu \mathrm{l}$; the digest was diluted to $50 \mu \mathrm{l}$ and ligated. The ligation mix $(1.0 \mu \mathrm{l})$ was used in protoplast transfection of strain CU267 and 100 visible plaques were obtained. Three phage isolates were purified, used to lysogenize strain CU267, and their DNA isolated from small-scale induced lysates. Their restriction maps were identical; all had lost the $3.4 \mathrm{~kb} X b a I$ fragment, and retained the expected $2.9 \mathrm{~kb} X b a \mathrm{I}-S m a \mathrm{I}$ fragment (Fig. $4)$. One of these phages was named $\phi 105 \mathrm{MY} 2$.

Strain AM677 was lysogenized with $\phi 105 \mathrm{MY} 2$, and with another two identical isolates. Five lysogens were tested for each lysate; all were Tzm-red $\left(\mathrm{Ger}^{+}\right)$. The DNA remaining in these hybrids was therefore sufficient to complement the gerC58 defect of strain AM677. The gerC gene is therefore contained in the $2.9 \mathrm{~kb} \mathrm{XbaI-SmaI}$ fragment of $\phi 105 \mathrm{MY} 2$, which can be easily isolated in quantity.

The cloned DNA which complements $g e r C$ is derived from the region defined genetically as the $\operatorname{ger} C$ locus, since the clone could recombine with (although not complement) the aroB mutation of strain SB137, as determined by a significant but low frequency of transduction by $\phi 105 \mathrm{MY} 1$ in spot transductions on selective minimal agar (Yazdi, 1989). Data from Southern blotting of the aro-trp region (D. Henner, personal communication) suggests that a $6 \mathrm{~kb} B c / \mathrm{I}$ fragment extends to the trp-distal side of aro, in the region that would be predicted from Fig. 2 to contain $\operatorname{ger} C$; this is similar to the estimated size of the cloned fragment. Recent preliminary sequence data confirm that the trpproximal end of the cloned DNA lies within the aroB gene (S. Greenhalgh, unpublished).

The $\operatorname{ger} C$ locus as defined by mapping is located close

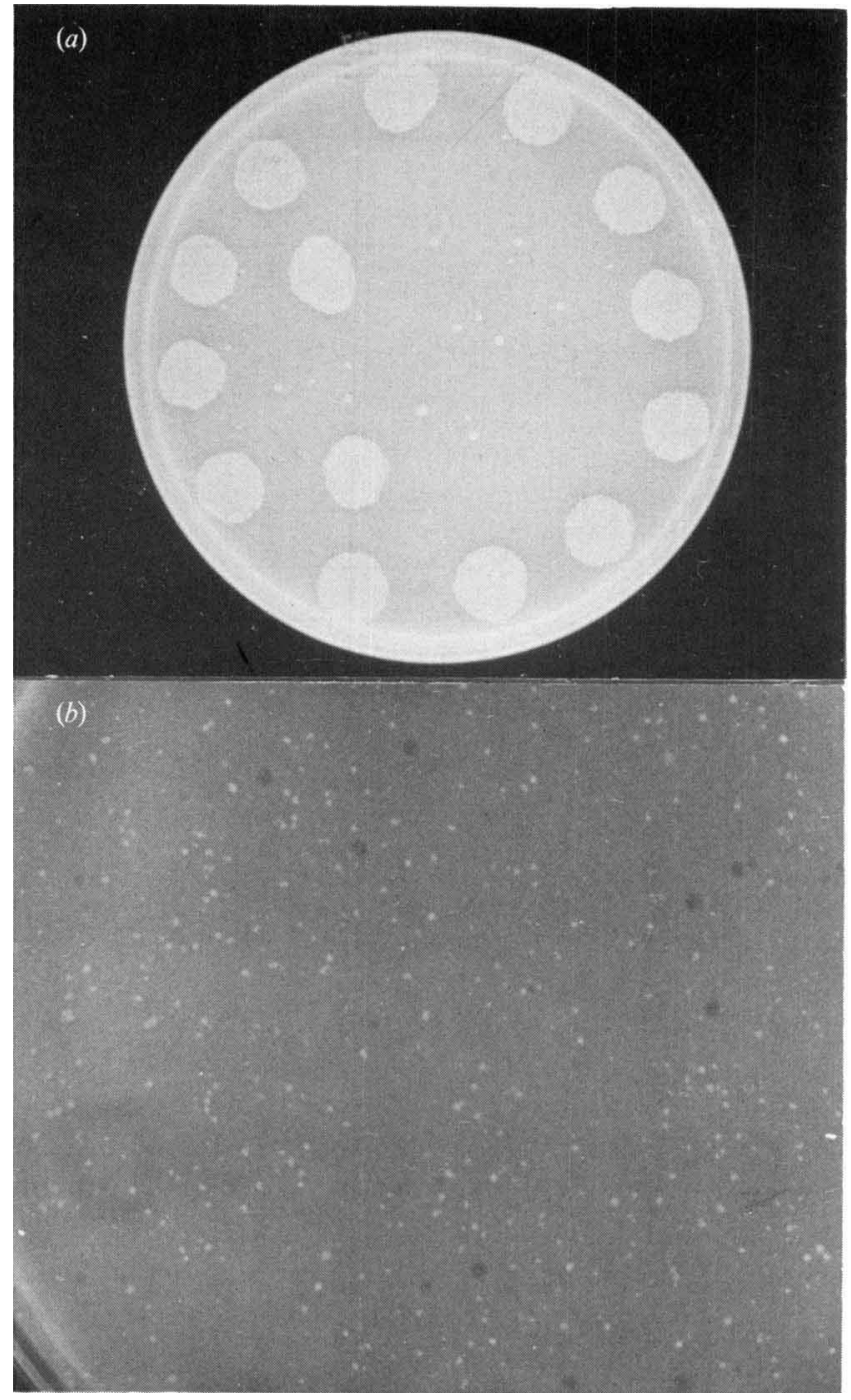

Fig. 3. Complementation of the Tny ${ }^{-}$growth defect by phage 105 MY1. (a) Ten microlitres of induced lysates were spotted on a lawn of Tnycells on NA, and the plates incubated at $30^{\circ} \mathrm{C}$ for $48 \mathrm{~h}$. On this plate 14 lysates were positive. The negative, vector, control is present in an area of the plate to the right of centre but the spot cannot be clearly seen. Tny ${ }^{+}$revertants or pseudo-revertants can be seen scattered throughout the surface of the plate. $(b)$ Complementation at the single-plaque level. One hundred microlitres of a $10^{3}$-fold dilution of a $\mathrm{CsCl}$-purified preparation of phage MY1 was plated with Tny cells in an overlay on NA and incubated overnight at $30^{\circ} \mathrm{C}$. The development of more densely-growing lysogens in invisible 'plaques' can be seen, as well as plaques of more normal appearance, generated by deletions in the transducing phage genome.

to several other markers; spoIVA (33\% cotransformed with $\operatorname{trpC2}$; Piggot \& Coote, 1976), mtr (40-55\% cotransformed with trpE; Hoch et al., 1971) and ecp ( $46 \%$ cotransformed with aro $B$, calculated from data in Raugei et al., 1981) are also reported as mapping in this region. Attempts were made to complement strains NG17.23, BG4004 and FB75. An area in a lawn of each strain on 

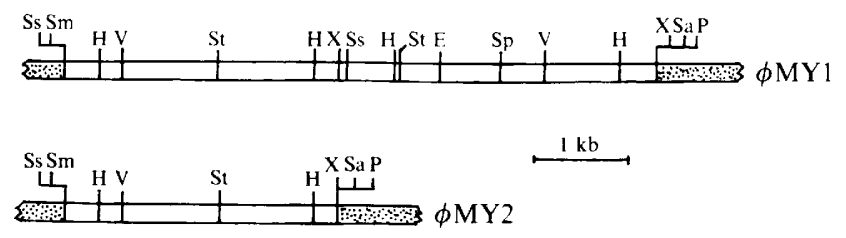

Fig. 4. Summarized restriction map of $\phi 105 \mathrm{MY} 1$ and its deletion derivative MY2. Vector DNA immediately flanking the $6.3 \mathrm{~kb}$ of cloned DNA is shown as a stippled region; restriction sites remaining in the multiple cloning site on either side of the insert are indicated. The actual fusion points of vector and cloned DNAs in phage MY1 are hybrid sites formed by fusion of $B a m H I$ and $B c l$ I cohesive ends. Phage MY2 was generated from MY1 by deletion of the internal $3.4 \mathrm{~kb} \mathrm{Xbal}$ fragment. E, EcoRI, H, HindIII, P, PstI, V, EcoRV, Sa, SaI, Sm, SmaI, Sp, SphI, Ss, SstI, St, StuI, X, XbaI.

NA was infected with a $10 \mu \mathrm{l}$ drop of $\phi 105 \mathrm{MY} 1$, estimated from DNA content to contain about $10^{7}$ phages $\mathrm{ml}^{-1}$. After overnight incubation at $30^{\circ} \mathrm{C}$, single colonies were isolated by streaking from the area of infection. After confirmation of their lysogenic status, the phenotype of 50 was tested in each case. None of the three markers was complemented by the cloned DNA. In this procedure repair by recombination would not be detected; in fact, the mtr-264 mutation can be repaired by recombination with the cloned DNA (D. Henner, personal communication). The spoIVA gene has now been cloned, and the restriction map of the ger $C$ region does not overlap with that of the spoIVA clone (J. Errington, personal communication).

The complexity of the original gerC strains and the difficulty in studying them because of linked mutations has led to the intensive analysis of only one of the two available; the second mutation, gerC 88 , generates anomalous mapping data (Moir et al., 1979; M. Yazdi, unpublished results), and the phenotype of a strain carrying a single mutation at this locus is not known. The strategy of first cloning the wild-type gene corresponding to gerC58 means that it should now be possible to establish whether the two mutant alleles map in the same place. Lysogens generated by infection of $\phi 105 \mathrm{MY} 2$ into a slow-growing ger- 88 strain grow at the same rate as the wild-type. This suggests that $g e r-88$ is also complemented by the cloned DNA. As both mutants came from the same mutagenesis (Trowsdale \& Smith, 1975) it is quite possible that they are differently suppressed derivatives of the same original mutation. The failure to obtain many gerC mutants in past mutagenesis regimes is not surprising, given the major growth defect that may result.

The nature of the $\operatorname{ger} C$ defect and how it is suppressed by an unlinked mutation remains obscure. Since the $\operatorname{ger} C$ defect causes a temperature-sensitive germination phenotype, it is more likely to be a missense than a nonsense mutation. The defect in germination is reversi- ble, as germination is initiated if the temperature is shifted back to the permissive from the non-permissive temperature (Trowsdale, 1973). If the gerC58 mutant gene encodes a protein with some degree of function in germination at low temperature it is surprising that the defect in growth is exhibited at all temperatures although the level of residual function required might be higher for growth. Even on minimal medium, the unsuppressed gerC mutant does not grow faster at $30^{\circ} \mathrm{C}$ than at higher temperatures. The suppression could be tRNA-mediated or could involve activation of an alternative function that would substitute for gerC in growth, but not in germination; alternatively some compensating mutation could have arisen in a gene whose product interacts with the gerC product. It is not clear at this stage whether a variety of different mutations can suppress gerC58, as no attempt has yet been made to analyse the suppression phenomenon.

The evidence suggests that the defects in growth and germination both result from the same gerC 58 mutation. The $\operatorname{ger} C$ gene would therefore be unlike all other ger loci so far identified, as its product is likely to have a role in both growth and alanine-stimulated germination. The putative gerC product would not, however, be involved in the alternative germination route requiring both an amino acid and sugars. The only other locus in which mutations have been found to affect alanine germination specifically is ger $A$, which is a developmentally regulated operon encoding three proteins that are probably membrane-associated (Zuberi et al., 1987); the model currently proposed is that the germinant L-alanine binds to a complex of these proteins and that the signal is somehow then transduced. The gerC gene product is implicated in this process, and may be involved in assisting the interaction with germinant or in transducing the initial stimulus. The likelihood that it represents a vegetative protein required for normal growth adds further to its interest and importance for our understanding of spore germination mechanisms.

We thank Dr D. Henner for discussion and Dr J. Errington for the supply of the cloning vector. M. A.Y. was the recipient of a Scholarship from the Ministry of Education, Iran.

\section{References}

Anagnostopoulos, C. \& Spizizen, J. (1961). Requirements for transformation in Bacillus subtilis. Journal of Bacteriology 81, 741746.

ERrington, J. \& Jones, D. (1987). Cloning in Bacillus subtilis by transfection with bacteriophage $\phi 105 \mathrm{~J} 27$ : isolation and preliminary characterization of transducing phages for 23 sporulation loci. Journal of General Microbiology 133, 493-502.

ERrington, J. \& Pughe, N. (1987). Upper limit for DNA packaging by Bacillus subtilis bacteriophage $\phi 105$ : isolation of phage deletion mutants by induction of oversized prophages. Molecular and General Genetics 210, 347-351. 
Feavers, I. M., Miles, J. S. \& MoIR, A. (1985). The nucleotide sequence of a spore germination gene (gerA) of Bacillus subtilis 168 . Gene 38, 95-102.

Feavers, I. M., Foulkes, J., Setlow, B., Sun, D., Nicholson, W., SETLOW, P. \& MoIR, A. (1990). The regulation of transcription of the gerA spore germination operon of Bacillus subtilis. Molecular Microbiology 4, 275-282.

Hoch, S. O., Roth, C. W., Crawford, I. P. \& Nester, E. W. (1971). Control of tryptophan biosynthesis by the methyltryptophan resistance gene in Bacillus subtilis. Journal of Bacteriology 105, 38-45.

JAMET, C. \& ANAGNOSTOPOULOS, C. (1969). Etude d'une mutation tres faiblement transformable au locus de la threonine desaminase de Bacillus subtilis. Molecular and General Genetics 105, 225-242.

JoNES, D. \& ERRINGTON, J. (1987). Construction of improved bacteriophage $\phi 105$ vectors for cloning by transfection in Bacillus subtilis. Journal of General Microbiology 133, 483-492.

MoIR, A. (1983). The isolation of $\lambda$ transducing phages carrying the citG and gerA genes of Bacillus subtilis. Journal of General Microbiology 129, 303-310.

MoIR, A. \& BRAMMAR, W. J. (1976). The use of specialised transducing phages in the amplification of enzyme production. Molecular and General Genetics 149, 87-99.

MoIR, A., LAFFERTY, E. \& SMITH, D. A. (1979). Genetic analysis of spore germination mutants of Bacillus subtilis 168: the correlation of phenotype with map location. Journal of General Microbiology 111, 165-180.

Nester, E. W., Schafer, M. \& Lederberg, J. (1963). Gene linkage in DNA transfer: a cluster of genes concerned with aromatic biosynthesis in Bacillus subtilis. Genetics 18, 529-551.

Piggot, P. J. \& CoOTE, J. G. (1976). Genetic aspects of bacterial endospore formation. Bacteriological Reviews 40, 908-962.

Piggot, P. J., MoIR, A. \& SMith, D. A. (1981). Advances in the genetics of Bacillus subtilis differentiation. In Sporulation and Germination, pp. 29-39. Edited by H. S. Levinson, A. L. Sonenshein
\& D. J. Tipper. Washington, DC: American Society for Microbiology.

Raugei, G., Bazzicalupo, M., Federici, G., Gallori, E., Pepino, R. $\&$ Polsinelli, M. (1981). Effect of a new pyrimidine analog on Bacillus subtilis growth. Journal of Bacteriology 145, 1079-1081.

SAmmons, R. L., MoIR, A. \& SmTth, D. A. (1981). Isolation and properties of spore germination mutants of Bacillus subtilis deficient in the initiation of germination. Journal of General Microbiology 124, 229-241.

Shimotsu, H. \& HenNer, D. J. (1986). Construction of a single-copy integration vector and its use in analysis of regulation of the trp operon of Bacillus subtilis. Gene 43, 85-94.

Trowsdale, J. (1973). Genetic studies of germination in Bacillus subtilis 168 . PhD thesis, University of Birmingham.

TROWSDALE, J. \& SMITH, D. A. (1975). Isolation, characterisation and mapping of Bacillus subtilis 168 germination mutants. Journal of Bacteriology 123, 83-95.

WARBURG, R. J. \& MoIR, A. (1981). Properties of a mutant of Bacillus subtilis 168 in which spore germination is blocked at a late stage. Journal of General Microbiology 124, 243-253.

Warburg, R. J., Buchanan, C. E., Parent, K. \& Halvorson, H. O. (1986). A detailed study of gerJ mutants of Bacillus subtilis. Journal of General Microbiology 132, 2309-2319.

YAZDI, M. A. (1989). Genetic and molecular analysis of the gerC spore germination locus of Bacillus subtilis 168. PhD thesis, University of Sheffield.

ZUBERI, A. R. (1985). A molecular analysis of the ger A spore germination locus of Bacillus subtilis 168. PhD thesis, University of Sheffield.

Zuberi, A. R., Feavers, I. M. \& MoIR, A. (1985). Identification of three complementation units in the ger $A$ spore germination locus of Bacillus subtilis. Journal of Bacteriology 162, 756-762.

ZUBerI, A. R., Feavers, I. M. \& MoIR, A. (1987). The nucleotide sequence and gene organisation of the gerA spore germination operon of Bacillus subtilis 168. Gene 51, 1-11. 